\title{
Ideology, Leaders and Employee Behaviour: An Integration of Transformational Leadership Theory
}

\author{
Rosemary B. Coffie ${ }^{1}$, Rachel Esi Coleman ${ }^{1}$ \\ ${ }^{1}$ Department of Human Resource and Organisational Development, KNUST, Ghana \\ Correspondence: Rosemary B. Coffie, Department of Human Resource and Organisational Development, \\ KNUST, Ghana.
}

Received: May 12, 2018

Accepted: June 2, $2018 \quad$ Online Published: June 15, 2018

doi:10.5539/ibr.v11n7p83

URL: https://doi.org/10.5539/ibr.v11n7p83

\begin{abstract}
Myriad of literature and studies on ideology articulate it as a concept and theory elaborating on its formation process, attributions and connotations; laying emphasis on it as a social or political science concept without inclining it to employee behaviour in businesses. This paper investigates the role of ideologies of leaders in their decision making and its effect on employee behaviour, focusing on entrepreneurs of SMEs and their employees in Ghana. The study adopts the quantitative approach using structured questionnaires as the main data collection tool. Considering conservatism and liberalism as the main forms of leadership ideologies, the transformational leadership theory is used as the lens to explain the authors' synthesised concept of leadership ideologies and employee behaviour. A regression analysis, utilising the tolerance statistical model, analysis of variance (ANOVA) and the variance inflation factor (VIF) is used to assess the multicollinearity (correlations) that exists between the variables. The coefficients of correlation reveal a positive relationship between leadership ideologies and employee behaviour. The study establishes that employee behaviour, to a limited degree is determined by the ideologies held by leaders. The researchers recommend liberalism as a more favourable leadership ideology for encouraging the realization of individual potentials of employees, enhancing creativity and cohesiveness at the workplace such as attained under transformational leadership.
\end{abstract}

Keywords: ideology, leadership, transformational leadership theory, employee behaviour, SMEs, decision making

\section{Introduction}

Recent studies have focused on the crucial role played by SMEs in the Ghanaian economy, highlighting their immense contribution to employment and income generation alongside factors that inhibit the operations of new and existing SMEs (Abor \& Bieke, 2006). Mensah (2004) identified SMEs as the "valve for absorbing" the redundant labour force in the Ghanaian economy. There exists no precise definition for SMEs, hence, researchers and authors have defined SMEs on the basis of some criterion relevant to the objective at hand. Capital assets, labour skill applied, legal status, turnover level and number of permanent and casual workers were recognized by Abor and Quartey (2010) as such criteria. The business environment unquestionably impacts businesses but entrepreneurs to a great extent affect their businesses by way of decision making with regards to situations that arise. Anwar and Hasnu (2013) noted that leadership impels the direction, spirit and discipline of an organization. Hence, as leaders of SMEs, entrepreneurs influence by means of the control exercised in decision-making (O'Regan \& Ghobadian, 2005) which is influenced by their ideologies towards the operations of these SMEs.

Implementation of decisions made in SMEs is not carried out by entrepreneurs alone: employees play a critical role in the realization of what has been conceived by the entrepreneurs. This renders the employees highly beneficial to SMEs, hence, the number of employees as one criterion in defining an SME (Teal, 2002). Given this debate, the question remains:

1. Do the ideologies held by leaders influence their decision making process in businesses?

2. Do the decisions made from these ideologies impact the behaviour of employees?

Consequently, this points out the need to examine how the ideologies held by entrepreneurs influence the behaviour of employees in addition to the process of decision-making in these SMEs. 
Ideologies comprise the incorporation of thoughts and causal beliefs influencing how people define problems and make decisions that converge to establish an individual's perception and attitude in a given situation(Kieser, 2001). "Leadership ideologies" is a term, formulated from the concept of ideologies but with strong emphasis on those ideologies held by individuals in leadership positions of business enterprises. The term "leadership ideologies" as coined by the researchers define the individual principles, philosophies, ideas and beliefs individually held by leaders in organisations, synthesized from the concept of ideologies and underlined by the transformational leadership theory.

Employee behaviour depicts the reactions of employees to situations that are encountered in the workplace. Hence, entrepreneurs should be particular about the kind of environment they create for their employees. Expectations of employee behaviour such as commitment, loyalty and attitude at the workplace ought to be aligned with the vision (resulting from leader's ideologies) since both can lead to the creation of a particular environment for employees. These serve as the background to which this study is conducted to investigate ideologies of leaders and how they influence employee behaviour.

The outline of the paper follows through from review of pertinent literature on leadership, elements of ideology, employee behaviour and the role of ideology in decision making in addition to the theoretical framework underpinning the study. This is followed by the methodology section which considers the tools and procedures in collecting and analysing data collected to tackle the research problem at hand. The last section discusses the findings of the study whereas the final section is dedicated to the summary of findings, conclusions implications, limitations, suggestions for further studies.

\section{Literature Review}

This section expounds on what leadership ideologies are, and how it impacts employee behaviour on the basis of the works of other researchers on leadership theories and ideologies and employee behaviour.

\subsection{Leadership Ideologies}

Leaders are obligated to develop the future vision and to motivate the organizational members to achieve the visions and improve organizational performance (Iqbal, Anwar, \& Haider, 2015). Owing to the fact that leadership greatly drives the direction, spirit and discipline of an organization, the ideologies held by leaders directly influence the ultimate purpose of existence of the business as identified by Anwar and Hasnu (2013). Therefore, leadership ideologies are established as having a positive relationship with the purpose of existence of business and this study follows to examine if same can be said of employees. Resulting from the fact that organizational vision, which sets the tune for activities in the organization, is determined by the ideologies of leaders of that organization (Anwar \& Hasnu, 2013), decisions taken in pursuit of the organizational vision (Lipton, 1996) are driven by the ideologies held by the leaders (Chen, 2003). Both of these (vision and decision) set the course and dictate activities undertaken in businesses as implemented by employees depicting leadership ideologies (ideologies of leaders) as a crucial notion in the field of management.

According to Pesqueux (2002), ideology as a concept, is exceptionally puzzling due to the "socialization" and "politicization" of the concept stemming from the major influences in its foundation: that of a political perspective with Marx and Engels and that of the sociological reaction. "Ideology" as a term was coined by Desttut de Tracy in 1796 as a "science of ideas" Weiss and Miller (1987), "the study of how we think, speak and argue" (Van Dijk, 2004). Many authors have reworded Desttut's conception of ideology since then by giving different statements. For instance, Walsh and Ellis (2004) explain ideology as implying a selective interpretation and understanding of the data that come to our sense, our general emotional picture of how things should be rather than an objective and rational evaluation of the evidence. For this study, the researchers define ideologies as a system of incorporated thoughts, beliefs, principles, ideas and philosophies emanating from particular social context held by an individual or group of individuals that unite to define their perception of information, define problems, determine decisions made and attitude in a given situation.

\subsection{Types of Ideologies}

There exists various forms of ideologies such as absolutism, constitutionalism, liberalism, nationalism, socialism, humanism, capitalism, universalism, communism and fascism as identified by Lowenstein (1953). Two forms of ideologies out of the numerous ideologies were deemed more satisfactory to this study by the researchers in context with the topic. These include conservatism and liberalism.

\subsubsection{Conservatism}

Conservatism (or conservativism) may be referred to as any political philosophy that prioritizes tradition (religious, cultural or nationally defined beliefs and customs) amidst external forces for change and is 
judgmental of propositions for radical change (Scruton, 1984). According to Alexander (2015), conservatives prefer the familiar to the unknown, the actual to the possible, the limited to the unbounded, the near to the distant, the convenient to the perfect. Conservatives contend that there is no compulsion to induct change on the basis that human imperfection and uncertain consequences render it impossible to ascertain whether change will be for the better (Stove, 2003). Conservative individuals in leadership positions claim that there is no need to adopt change, for reason that human imperfections and uncertain consequences render it impossible to predict whether change will be better or not (Stove, 2003). Consequently, resistance to change- especially in the workplace is very abstract and a negative moment of conservatism as conservatives look backwards and are not interested in forward matters. (Alexander, 2015).

\subsubsection{Liberalism}

As a moral and political philosophy, liberalism is founded on two main principles which are individualism and liberty (Chau, 2009). Arguing that the highest social value order is one that is centred on the individual, liberalism places the individual at the core of society. Society therefore purposes to allow the individual reach their full potential at their own will; it is from these principles that the elements of liberalism emanate. Liberals seek "to indicate the right of the individual to shape his own destiny, regardless of any authority which might seek to limit his possibilities" (Alexander, 2015). The elements of liberalism include individualism, egalitarianism, universalism and meliorism.

\subsubsection{Elements of Liberalism}

Individualism belief places value on individuality; advocates the belief that just by virtue of being a human being confers on an individual a pre-political right above the discretion of the state as conferred on an individual, since an individual is viewed as rational and able to make decisions (Chau, 2009). Thus, individualism intensifies an individual's sense of rights, declaring laissez faire by abandoning the individual to his own rights. These rights are however subjected to the harm principle which purports that as long as individuals do not harm one another, they are free to do what they want (Chau, 2009).

Furthered by the classic liberals, egalitarianism (referred to as fairness or justice) signifies equal opportunity in political and legal sense, not in the sense of redistributing wealth equally. Egalitarianism advocates that good people should be dealt with fairly and bad people be treated contrary (Campbell, 1991). It includes principles such as treating relevant cases similarly and not discriminating, eschewing the act of exploiting innocent people, not profiting from wrong keeping promises, rewarding merit and giving punishment in proportion to crime committed (Chang, 2002).

Universalism purports that the moral principles of individualism are binding on all individuals. Universalism explores systematic norms or laws imposed on all individuals - both rich and powerful to ensure order. Universalism esteems production for the masses and in pursuit of treating everyone the same, it wrongly treats emotions by considering it as if it is "numerical" (Hampden-Turner \& Trompenaars, 2000).

Meliorism is of the belief that individuals have the capacity of getting better even as social and political institutions can get better (Chau, 2009). Meliorism comprises of humanism and pluralism and holds that individuals are competent in creating a better world and a better self, thus meliorism centres on what individuals can do to facilitate a progressive world since better futures can only be realized through efforts of individuals who hope to live it (Koopman, 2006).

\subsection{Role of Ideology in Decision-Making}

Ideologies map out what is considered a desired system of beliefs, ideas, world-view, norms, or inclinations by an individual or a group. Ideologies are composed of explicit and implicit conceptions and thoughts concerning existences that arise from a particular social context (Chen, 2003). This implies that ideologies play an imperative role in how entrepreneurs view the world and conduct activities as much as how they expect employees in SMEs to also view the world. Daft (1998) and Dessler (1998)suggest that leaders tend to adopt a more structured decision making process which is based on accurate and relevant fact, research and analysis of data and information (Rue \& Byars, 2003; Simmon, 1979).

In the primary step of the decision-making process, the ideologies held by individuals have an impact on the identification of the decision requirements. Differing ideologies results in the distinctive analysis of situations and causes (Chen, 2003). For instance, an entrepreneur with dominant motive of maximizing profit probably will analyse causes differently from another entrepreneur driven by passion or social concern for others. Differences in ideologies also account for differences in alternatives that are probably considered acceptable or unacceptable by entrepreneurs. Ideologies still come to play when predicting the criteria and paradigm upon which an 
alternative of choice is made and how it is evaluated (Balkin, 2002).

\subsection{Employee Behaviour}

Employee behaviour depicts the reactions of employees to situations that are encountered in the workplace and as such should not be counter-productive. In relation to this study, employee behaviour is analysed on the basis of employee commitment, attitude and loyalty. Factors such as job security and responsibilities, organizational culture (which to some extent is influenced by ideologies of leaders), communication and teams within which employees find themselves have major influence on employee commitment, attitude and loyalty (De Jong \& Den-Hartog, 2007; Niehoff, Moorman, Blakely, \& Fuller, 2001).

\subsection{Employee Attitude}

Attitude is described as a psychological tendency articulated by evaluating a precise entity with some degree of like or dislike (Eagly \& Chaiken, 1998). "Attitude is referred to as the hypothetical construct representing an individual's degree of like or dislike for an item. Attitudes are generally positive or negative views of a person, place, event or thing (Bagherian, Goodarzi, \& Shadfar, 2011); these views known as attitude object, is an individual's view of change and not a physical entity that is independent of the individual (Visagie, 2010). Individual attitudes therefore determine behaviour and emotions exhibited by an individual to his environment or surroundings. Hence employee attitude portrayed in an organization is either positive or negative.

\subsection{Employee Commitment}

Employee commitment is defined as the psychological state characterizing an employee's relationship with an organization and its implications on their decision to continue as an employee in the organization (Allen \& Meyer, 1990). Employee commitment considers the extent to which an individual identifies with an organization and how involved an individual is in an organization. A committed employee "is bonded by the organization such that it reduces the likelihood of turnover" (Meyer, Becker, \& Vandenberghe, 2004 p.993). Studies undertaken on commitment indicate its influence on both individual and organization - whether high or low(Brockner, Tyler, \& Cooper-Schneider, 1992), directly related to increased satisfaction, performance, and organizational adaptability ((Lok \& Crawford, 1999; Meyer et al., 2004) in addition to decreased absenteeism and employee turnover (Lo, Ramayah, \& De Run, 2010).

In analyzing the dimensions of employee commitment, our study adopts the Allen and Meyer (1990) conceptualization. The authors identified three dimensions of employee commitment namely; affective commitment where an employee decides at will to continue with an organisation, continuance commitment in which employees continue with an organization rather than leave due to some investments they perceive to have made in the organisation and a recent aspect known as normative commitment which arises when employees sense they are obligated to continue with an organisation (Allen \& Meyer, 1990).

\subsection{Employee Loyalty}

Antoncic and Antoncic (2011), argue that "the loyalty of employees exists when employees believe in the objectives of the company, accept the objectives as their own, work for the common welfare, and want to stay with the company" (p. 82). As an action, loyalty emanates from the honest motives of employees in their pursuit of the organizational goals (Pfeiffer, 1992). As "a form of commitment" (Elegido, 2013, p 499) loyalty requires conscious efforts on the part of employees to "further the best interests of [their] employer even when doing so may demand sacrificing some aspects of [their] self-interest beyond that required by one's legal and other moral duties" (Elegido, 2013, p. 496) Loyalty is the readiness to forgo personal needs in favour of a relationship (Reichheld, 2001), as cited in Kumar and Shekhar (2012). Loyalty is a position that one takes owing to a supposed obligation and reciprocity Hart and Thompson 2007 as cited in (Kumar \& Shekhar, 2012).

As stated by Antoncic and Antoncic (2011), "the loyalty of an employee can be expressed through a feeling of the individual to belong to the company and the team of co-workers, whom he or she wants to help..." (p. 82). Loyal employees perform highly in the workplace by focusing on the bigger picture and are driven by the interest of employers. Elegido (2013) identified three things considered by employees in contemplating loyalty to employers;

i. "That loyalty shown an employee can be conducive to human flourishing..."

ii. "That a loyal employee tends to have a greater motivation to work"

iii. "A loyal employee is inherently considered "more trustworthy" than a disloyal employee (p. 498-501). 


\subsection{Transformational Leadership Theory}

Burns (1978) introduced the concept of transformational leadership which was used to describe the political leadership that transformed the values of its followers by causing followers to view themselves and situations differently than the followers previously did. However, (Bass, 1997, 1998) further developed the scope of transformational leadership to embrace business organizational settings. By providing a vision for the organization, transformational leaders align the goals of subordinates with that of the organization to stimulate subordinates towards achieving the results as expected by leadership (Bass, 1997). Transformational leadership comprises four components; inspirational motivation, idealized influence, individualized consideration, and intellectual stimulation.

Inspirational motivation is depicted in how effectively transformational leaders are able to communicate vision and arouse enthusiasm in workers whilst inspiring workers to achieve results. Thus when transformational leaders speak of vision for the future they do so with much zeal to heighten such feelings in the workers (Dubinsky, Yammarino, Jolson, \& Spangler, 1995). Idealised influence implies the exhibition of certain behaviours by leadership when influencing followers, which put leaders in the place of role models for the followers. Such behaviours may be depicted through the transformational leaders' emphasis of group benefits over personal ones and conformance to strong ethics in his personal as well as group endeavours (Bono \& Judge, 2004). Individualized consideration involves transformational leaders providing attention to the relevant individual needs of followers (Judge \& Bono, 2000), in order to facilitate personal development of followers (Bass, 1997). Intellectual stimulation entails the "creation of a culture of creative thinking" to engage followers more in the organization (Tims, Bakker, \& Xanthopoulou, 2011). Studies undertaken in this area (De Groot, Kiker, \& Cross, 2000; Judge \& Piccolo, 2004; Wang \& Zhu, 2011) indicate a high level of performance in followers of transformational leaders. Bass (1997) believes transformational leaders enhance the self-worth of followers by treating them on individual basis (individual consideration) and encouraging creativity and new ways of viewing problems (intellectual stimulation) in followers.

\subsection{Transformational Leadership and Ideology}

Transformational leadership entails the involvement and nurturing of motivation among leaders and followers towards the realization of the vision set by the transformational leader. The theory of transformational leadership explained above serves as lens to this study as transformational leaders command the required behaviour (attitude, commitment and loyalty necessary for performance) by influencing the outlook employees have of themselves and situations (Bass, 1998). Hence, ideologies can be predicted as coming into play- considering the definition of ideology as a comprehensive vision, as a way of looking at things, as in common sense and several philosophical tendencies, or as a set of ideas proposed by dominant class of society to all members of the society (Wellington, 2002). Krishnan (2005) recognized that followers' terminal value system congruence and identification are influenced by the association and duration of their attachment with transformational leaders.

As recognized by Bass (1997), transformational leaders influence followers through inspirational motivation, idealized influence, individualized consideration, and intellectual stimulation. All of these are aimed intrinsically at the employees- reshaping their thought patterns, values, goal congruence and tendencies to be aligned with the vision of the transformational leader thus, catalysing the process of realizing the vision set by the transformational leader. Accordingly, as followers (employees) are exposed to the motivation, influence and consideration stimulated by transformational leaders, they are more prone to conform to world-view and adopt certain tendencies deemed as favourable in the "new light" of approaching situations. To what extent this is realized among entrepreneurs and employees is the question researchers must address. 


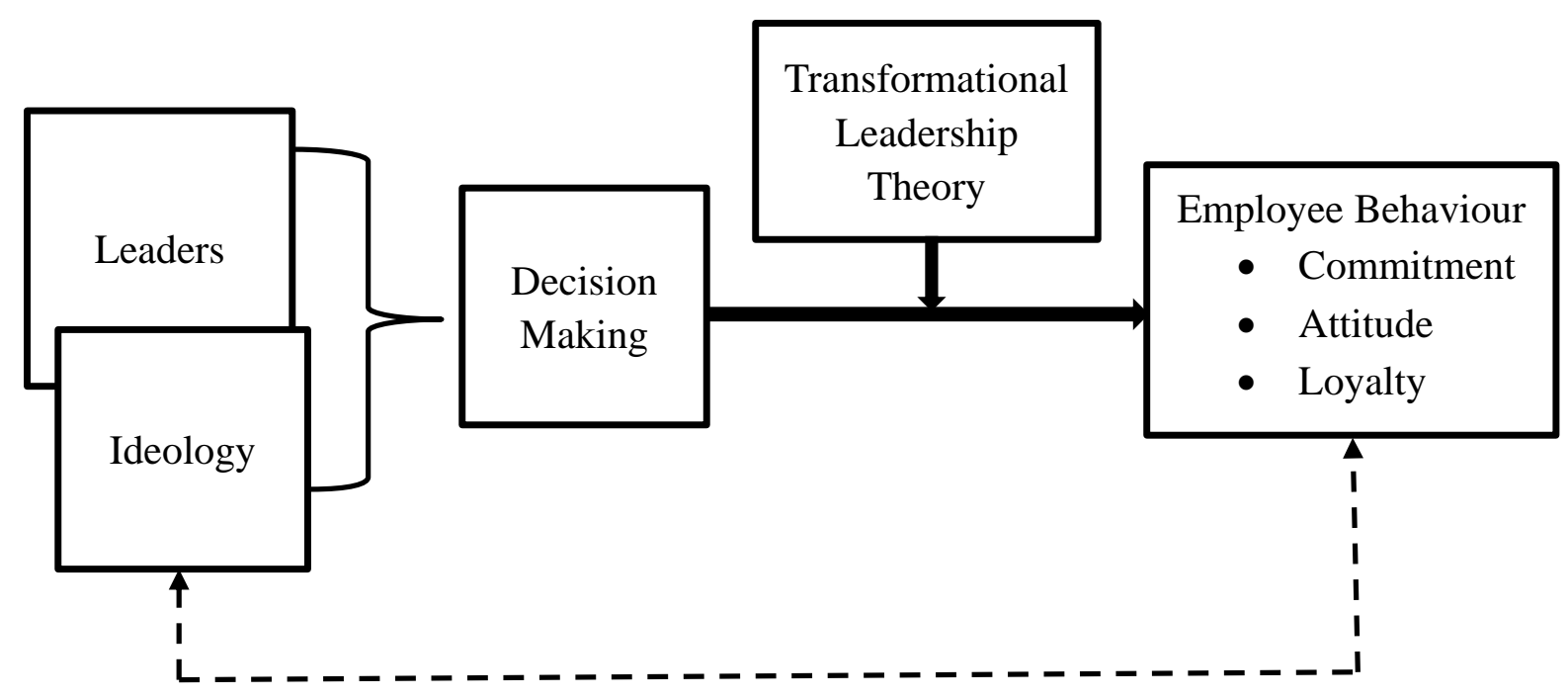

Figure 1. Conceptual Framework

Source: Researchers Construct 2017

From the conceptual framework, leaders and their ideology constitutes the independent variable which influences the dependent variable - employee behaviour. The relationship is however affected by a third variable transformational leadership which moderates this relationship. This moderating effect results from the alignment of employee behaviour to the vision set by the transformational leader. To this extent, the researchers predict that the ideology (principles, philosophies and worldviews) of leaders reflect in their decisions as far as an organization is concerned by implementing plans resulting from decisions made and employees align their behaviour by exhibiting attitude, loyalty and commitment necessary to realizing the vision set by leaders. Leaders' decision-making to this end, functions as the mediating variable for the study, as leaders exhibit their ideologies through their decision making. Once a decision is made, then employees will react to such decisions.

\section{Methodology}

This work adopted an explanatory study approach to investigate the casual relationship between the variables, leadership ideologies and employee behaviour. Therefore, a survey was embarked on among selected SMEs in some regions in the southern sector of Ghana namely: Central, Greater Accra and Ashanti regions. A quantitative research which lays emphasis on the quantification and measurement in data collection and analysis (Bryman \& Bell, 2015; Creswell \& Clark, 2007) was adopted by the researchers to evaluate the influence of the ideologies held by leaders on the behaviour of employees.

\subsection{The Sample}

A total of 466 respondents comprising of 205 entrepreneurs of SMEs and 261 employees in these enterprises were selected for the study. The purposive sampling technique was used to select the entrepreneurs. This type of sampling was used because the inclusion of an entrepreneur as a respondent for the study was dependent on his business being classified as an SME. On the other hand, a simple random sampling was used to select the employees in the enterprises of the selected entrepreneurs. Again, this sampling seemed appropriate because every employee in the selected entrepreneur's work place equally qualified to be a respondent. The nature of the data was mainly primary sourced from the entrepreneurs and employees of the selected SMEs.

\subsection{The Questionnaire}

A structured questionnaire in the form of a Likert scale was the main instrument used for data collection. Given that the design of the questionnaire influences the response rate and the content validity and reliability of the collected data (Brace, 2008; Saunders \& Lewis, 2012), the researchers conducted a pilot study to arrive at a proficient questionnaire for data collection. By so doing, the questions that were inappropriate were improved, revised or removed, before the administration of the questionnaires to respondents.

\subsection{The Analysis}

The analysis of data was mainly quantitative, the researchers utilised a regression model in the examination of 
the tolerance level of variables studied through the analysis of variance (ANOVA). In addition, the Variance Inflation Factor (VIF) was used to measure the relationship existing between the pairs of variables studied by assessing the multicollinearity (correlations) simultaneously present in the regression analysis.

To verify the accuracy of the data, a reliability test was conducted on the research instruments used to conduct the study. The reliability analysis was examined using 15 items from the questionnaire. Table 4.1 below shows the reliability results.

Table 1. Reliability Statistics

\begin{tabular}{ll}
\hline Cronbach's Alpha & No. of Items \\
\hline 0.829 & 15 \\
\hline
\end{tabular}

Source: Researchers Field Data, 2017.

Based on the Cronbach's Alpha coefficient result shown in the table above, it can be understood that all the scale for the variables exceeded the conventional acceptable value 0.6 (Gliem \& Gliem, 2003) and thus attest to be reliable to be used for the analysis.

\section{Results of the Study}

The researchers investigated the relationship between leadership ideologies in their decision making and employee behaviour. The analysis below has been done to show these relationships separately.

In analysing the relationship between the Leadership ideology and employee behaviour a model summary was done. This is depicted in the model table below.

Table 2. Model Summary

\begin{tabular}{lllllll}
\hline Model & $\mathrm{R}$ & R Square & Adjusted R Square & Std Error of the estimate & Anova & \\
1 & $.692^{a}$ & .479 & .419 & .890 & $\mathrm{~F}$ & Sig. \\
& & & & & 7.948 & $0.000^{b}$ \\
\hline
\end{tabular}

\section{a. Dependent variable: Employees behaviour}

\section{b. Predictors: (Constant), Leadership ideologies}

\section{Source: Field study, 2017}

From the model, the adjusted $\mathrm{R}$ square which measures the proportion of variation in the dependent variable (Employees behaviour) being accounted for by the independent variable (Leadership ideologies) was 0.419, indicating that the predictors (Leadership ideologies) explains approximately $42 \%$ of the variation in employee behaviour. The analysis of variance (ANOVA) which had a p-value of $(0.000<0.05)$ was not significant. This shows that the regression model best fits the data. The researchers also looked at the Tolerance level of these

Table 3. Relationship between Leadership Ideologies and Employee Behaviour

\begin{tabular}{|c|c|c|c|c|c|c|c|}
\hline \multicolumn{8}{|c|}{ Coefficients $^{\mathrm{a}}$} \\
\hline \multirow[t]{2}{*}{ Model } & \multicolumn{2}{|c|}{$\begin{array}{l}\text { Unstandardized } \\
\text { Coefficients }\end{array}$} & \multirow{2}{*}{$\begin{array}{c}\text { Standardized } \\
\text { Coefficients } \\
\text { Beta }\end{array}$} & \multirow[t]{2}{*}{$\mathbf{T}$} & \multirow[t]{2}{*}{ Sig. } & \multicolumn{2}{|c|}{ Collinearity Statistics } \\
\hline & B & Std. Error & & & & Tolerance & VIF \\
\hline (Constant) & .415 & .427 & & .973 & .331 & & \\
\hline CI 1 & .080 & .059 & .076 & 1.340 & .181. & .837 & 1.195 \\
\hline CI 2 & .227 & .056 & .231 & 4.072 & .000 & .840 & 1.190 \\
\hline CI 3 & .106 & .052 & .122 & 2.038 & .043 & .759 & 1.317 \\
\hline LI 1 & -.197 & .047 & -.239 & -4.170 & .000 & .825 & 1.213 \\
\hline LI 2 & .120 & .057 & .132 & 2.113 & .036 & 699 & 1.431 \\
\hline 1 LI 3 & .266 & .056 & .293 & 4.771 & .000 & .721 & 1.387 \\
\hline $\mathrm{EBC}$ & .232 & .061 & .217 & 3.825 & .000 & .840 & 1.190 \\
\hline $\mathrm{EBC}$ & -.029 & .064 & -.027 & -.447 & .656 & .763 & 1.310 \\
\hline EBA & -.191 & .067 & -.186 & -2.851 & .005 & .636 & 1.572 \\
\hline EBA & .178 & .069 & .173 & 2.597 & .010 & 609 & 1.643 \\
\hline EBL & -.090 & .063 & -.095 & -1.433 & .153 & 617 & 1.620 \\
\hline EBL & .178 & .077 & .163 & 2.325 & .021 & .551 & 1.814 \\
\hline
\end{tabular}

a. Dependent Variable: My behaviour in the workplace is driven by my leader's ideology. CI=Conservatism Ideology,

LI=Liberalism Ideology, EBC=Employee behaviour(Commitment), EBA=Employee behaviour(Attitude),

EBL=Employee behaviour(Loyalty)

Source: Researchers field Work 2017

$\overline{\text { variables. This was used to assess the multicollinearity (correlations) between pairs of variables. It was computed }}$ as $1-R^{2}$. A small tolerance value (usually below 0.1 ) indicates that the variable under consideration is a perfect linear combination of the other independent variables. If a low tolerance is accompanied by a large standard error 
and non-significance, then a high correlation is said to exist between the variable and other variables. Inferences from the coefficient table indicate that, the tolerance for all of the variables are all above 0.1 (the threshold). This shows that there exists a correlation between employees' behaviour and that of leadership ideologies, but the relationship is not too strong. Nevertheless, the strength of all the variables correlated is less than $50 \%$.

The variance inflation factor (VIF) was also used to measure the relationship between the variables leadership ideology and employee behaviour. Usually VIF measures the multicollinearity among all the variables simultaneously. A high VIF $(\geq 10)$ shows that there exists a strong correlation between the variables. From the analysis, we observe that none of the values under the VIF column is above 10. The highest is 1.958 corresponding to 'my leader values status quo'. This implies that there is no strong correlation between employees' behaviour and leadership ideologies. The result of the study attests to the findings of Meyer et al. (2004) which concluded that normative commitment by employees comes naturally due to how they are nurtured by society. This is evident in commitments such as marriage and family, resulting in a feeling of being obligated morally to work. Studying the strength of the correlation in the table, it clearly shows that the relationship between liberal leadership and ideologies is stronger than the relationship between the conservative leadership and ideologies of SME leaders in the southern sector of Ghana.

\section{Role of Ideologies Held by leaders in Decision Making}

Leadership ideologies influence how leaders define problems and make decisions (Kieser, 2001) by stimulating selective interpretation and understanding of situations at the workplace in addition to information required; rendering the role of leadership ideologies in decision-making a crucial aspect of this study to be analysed. Researchers investigated the extent to which the leaders' ideologies influence decision-making by analysing the correlation that exists between the two variables, thus decision-making is dependent on leadership ideologies. This is depicted in the tables below.

\section{Nature of the relationship between Ideologies and Decision-Making}

Table 4. Model Summary

\begin{tabular}{lllllll} 
Model & $\mathrm{R}$ & R Square & Adjusted R Square & Std Error of the estimate & Anova \\
1 & $.430^{a}$ & .184 & .147 & .944 & $\mathrm{~F}$ & Sig. \\
& & & & & 4.902 & $0.000^{b}$ \\
\hline
\end{tabular}

a. Dependent variable: decision making

\section{b. Predictors: (Constant), Leadership ideologies}

Source: Researchers Field work, 2017

From the model, the adjusted $\mathrm{R}$ square which measures the proportion of variation in the dependent variable (Decision making) that is being accounted for by the independent variable (Leadership ideologies) was 0.430 . This means that the predictors (Leadership ideologies) explain approximately $43 \%$ of the variation in decision making as shown in the model.

Table 5. Relationship between ideology and decision making

\begin{tabular}{|c|c|c|c|c|c|c|c|}
\hline \multicolumn{8}{|c|}{ Coefficients $^{\mathrm{a}}$} \\
\hline \multirow[t]{2}{*}{ Model } & \multicolumn{2}{|c|}{ Unstandardized Coefficients } & \multirow{2}{*}{$\begin{array}{c}\text { Standardized Coefficients } \\
\text { Beta }\end{array}$} & \multirow[t]{2}{*}{$\mathbf{T}$} & \multirow[t]{2}{*}{ Sig. } & \multicolumn{2}{|c|}{ Collinearity Statistics } \\
\hline & B & Std. Error & & & & Tolerance & VIF \\
\hline (Constant) & 3.132 & .443 & & 7.067 & .000 & & \\
\hline IDL 1 & -.112 & .060 & -.143 & -1.882 & .061 & .727 & 1.375 \\
\hline IDL 2 & -.041 & .070 & -.043 & -.587 & .558 & .766 & 1.306 \\
\hline IDL 3 & -.031 & .081 & -.029 & -.383 & .702 & .742 & 1.347 \\
\hline IDL 3 & .014 & .088 & .015 & .163 & .871 & .529 & 1.892 \\
\hline IDL 4 & .356 & .075 & .393 & 4.776 & .000 & .618 & 1.619 \\
\hline IDL 5 & -.150 & .072 & -.201 & -2.087 & .038 & .452 & 2.214 \\
\hline IDL 6 & -.090 & .107 & -.083 & -.840 & .402 & .429 & 2.329 \\
\hline IDL 7 & .168 & .110 & .158 & 1.520 & .130 & .387 & 2.586 \\
\hline IDL 8 & .048 & .057 & .065 & .833 & .406 & .696 & 1.436 \\
\hline
\end{tabular}

a. Dependent Variable: Decision-making. Independent variable is ideologies

Source: Researchers Field Work, 2017

We can also infer from the coefficient table 5 that the tolerance for each of the variables was all above 0.1 (the threshold). This shows that there exists a correlation between decision making and leader's ideologies, but the correlation is weak. In addition, the variance inflation factor (VIF) was employed to establish the multicollinearity between the leadership ideologies and decision-making variables. A high VIF $(\geq 10)$ gives an indication that there exists a strong correlation between the variables. From the analysis, the researchers observed that none of the values under the VIF column was above 10 . The highest was 2.586 corresponding to (I make decisions based on personal orientation). This implies that there exists no strong correlation between decision making and leadership ideologies. 
These verify the findings of researchers that organizational vision which sets the tune for activities in the organization is determined by the ideologies of leaders of that organization (Anwar \& Hasnu, 2013) and decisions taken in pursuit of organizational vision (Lipton, 1996) are to some extent driven by the ideologies held by the leaders (Chen, 2003). In addition to the fact that all of these (vision and decision) set the course and direct activities undertaken in the organization which are mostly implemented by employees.

It is realized that despite the fact that ideologies influence to some extent decisions made by leaders, leaders also tend to adopt a structured decision-making processes, that are timely, based on accurate and relevant facts, research and analysis of data and information. This is because majority of decisions are not based on facts but rather on feelings and what leaders perceive as right are mostly unsuccessful owing to the fact that they are hard to defend and confronted by setbacks during implementation. Decisions based on reliable information and verifiable data on the other hand, are successful by means of sufficient time invested into extensive research on alternatives and assessment of the implications that follow (Chen, 2003).

With reference to the analysis, transformational leadership as a theory underpinning this work aided the researchers in defining the relationship predicted as existent between leadership ideologies and employee behaviour. Given that the transformational leadership process involves the influence of leaders in conforming the worldview of followers to that which is favourable to the set vision, leadership ideologies were predicted as those "worldviews" of the leader that were transmitted to employees whilst aligning their views to the vision of the transformational leader. However, in the analysis, it was realised that leadership ideologies do not solely determine the behaviours exhibited by employees in the workplace. Thus, employees themselves regulate individually, the degree to which they are influenced by leadership ideologies. The transformational leadership component accounting for this result of change in employee behaviour with regards to the adopted theory is intellectual stimulation. Intellectual stimulation entails "the creation of a culture of creative thinking" in organisations to increase employee engagement (Tims et al., 2011). Thus, leadership ideologies may not explicitly, to a greater extent, account for change in behaviour of employees, but other factors arising from the kind of culture built by leaders in organisations influence behaviour of employees do so. Consequently, the creation of a conducive environment by transformational leaders to encourage creativity and new ways of solving problems (intellectual stimulation) results in increased performance among employees.

A reduced rate of influence of employee behaviour by leadership ideologies therefore, points out the fact that, not all employees subject themselves to the ideologies of employers who exercise control over the activities of employees in the workplace.

\section{Discussion}

This study sought to investigate the extent to which ideologies of leaders influence their decision making and employees' behaviour.

The key findings the researchers identified were that;

- Leaders do not judge situations in the light of their ideologies alone.

- Decisions made by leaders do not solely emanate from ideologies but also are resultant of accurate and relevant facts pertaining to the situation at hand.

- Employee behaviour to a limited degree is determined by the ideologies held by leaders. However, it is also driven by factors such as job security and responsibilities, organizational culture, communication and teams within which employees find themselves.

For entrepreneurs, business performance is extremely dependent on decision-making, rendering it imperative to identify the role that their ideologies play in the process of decision-making (O'Regan \& Ghobadian, 2005). Whether decisions pertained to daily situations encountered by leaders or long-term ones which relate to an organization's vision; it was predicted that the situations at hand may be judged in the light of the ideologies held by leaders (Anwar \& Hasnu, 2013). Thus, with regard to the decision requirements, alternatives available and the final choice of action to be undertaken is determined by leaders for their subordinates (Dessler, 1998, pp.108). To ascertain these specific decision-making scenarios were presented to respondents to indicate the extent to which they agree or disagree with the statements presented in structured questionnaires. The data collected was analyzed to identify the relationship between leadership ideologies and decision making.

Our findings revealed an existing relationship between the two variables; the relationship however, was a weak one. The researchers realised that the weak relationship was accounted for by the fact that, most leaders or entrepreneurs from the selected SMEs also tend to adopt a structured decision-making process (Daft, 1998, pp.402), which was based on accurate and relevant facts, research and analysis of data and information. Rather 
than rely solely on their ideologies to selectively interpret information that they perceived whilst making decisions, leaders tend to also objectively evaluate and rationalize the situation or problem at hand, alternatives and final choice to be made (Rue \& Byars, 2003). In a structured decision-making process, decision-making is timely and based on accurate and relevant facts, research and analysis of data and information (Simmon, 1979). Whereas decisions based on feelings are mostly futile because they are hard to defend and are confronted with major setbacks during implementation (Chen, 2003), decisions based on reliable information and verifiable data are successful by means of sufficient time invested into extensive research on alternatives and assessment of the implications that follow. However, decision-making by leaders are driven by other factors such as accurate and reliable facts and analysis of information regarding the problem to objectively evaluate the situation (Rue \& Byars, 2003).From the analysis on the relationship between leadership ideologies and employee behaviour, it was inferred that the relationship between the two variables was not strong enough to conclude that employee behaviour is influenced by leadership ideologies that reflected in the decisions made by the entrepreneurs, which were in turn implemented by employees. Some other factors such as job security and responsibilities, organizational culture (which to some extent is influenced by ideologies of leaders), communication and teams within which employees find themselves, have major influence on employee commitment, attitude and loyalty (De Jong and Den Hartog, 2007; Niehoff, et al., 2001).

In this discussion, the integrative function of transformational leadership is realised in the degree to which the behaviour of employees is influenced by the ideology held by leaders. The finding of approximately $42 \%$ variation in the behaviour of employees ensuing from the ideology of leaders is ascribed to the association of employees with transformational leaders. This finding is affirmed by Krishnan's (2005) study which revealed that change in the employees' terminal value system is congruent and identified as resulting from their association with transformational leaders. The integration of transformational leadership in relation to ideology of leaders and employee behaviour entails; inspirational motivation, idealised influence, individualised consideration and intellectual stimulation (Bass, 1997), all of which are intrinsically directed at the employees reshaping their thought patterns, values, goal congruence and tendencies to be aligned with the vision of the transformational leader.

\section{Research Implications}

Findings of the study imply liberalism as a more favourable ideology to all entrepreneurs since liberal leaders foster a work environment that thrives on delegation; allowing employee autonomy for creative thinking and innovativeness on the part of employees. Under liberal leadership, businesses have a greater probability of surviving in the turbulent business environment providing such businesses are able to compete better in the market driven by innovation resulting from the creativity of employees, provision of value for customers and increased productivity. Furthermore, employees exhibit a higher level of loyalty and commitment under liberal leaders who provide them with equal opportunities. Liberalism also aids the decision-making process by informing leaders of new ways of seeing and handling situations.

Transformational leadership thus, integrates leaders' ideology and employee behaviour through the process of inspirational motivation, idealized influence, individualized consideration and intellectual stimulation. The study implies that as employees remain exposed to the motivation, influence and consideration stimulated by transformational leaders, employees are prone to conform to leaders' world-view and adopt certain tendencies deemed as favourable in the "new light" of approaching situations. Consequently, the adopted tendencies and world-views manifest in the behaviour exhibited by employees.

\section{Limitations, Further Research and Conclusion}

Inherently, the study was conducted on a wide coverage area in Ghana hence the cost incurred are limiting factors. Notwithstanding, one setback to this study was the unwillingness on the part of some entrepreneurs and their employees in disclosing information for the study in the data collection process. It was only the assurance of anonymity that helped. Another limitation was the inadequate information from literatures and research work in the area of study since not much work relating to our topic of study has been undertaken especially on SMEs in the Ghanaian sub region for that matter. Considering these limitations, future studies can be conducted to identify the role of Leaders' ideology in determining employee performance, focusing on other forms of businesses other than SMEs.

In concluding this study, it is vital to note that leadership ideologies affect decision making but not to a higher degree given that leaders tend to adopt structured decision-making processes based on relevant facts rather than feelings, contrary to always making decisions on the basis of feelings and what they perceive as right in the light of ideologies alone, in order to avoid difficulty in defending such decisions and setbacks during implementation. 
Employees' attitude, loyalty and commitment to a little extent responds to conservatism or liberalism in leadership. It can thus be concluded that leadership ideologies affect employees but also not so significant, whereas loyalty, attitude and commitment of employees decline as leaders become more conservative. The completion of this study contributed to the wealth of knowledge available on the role of ideologies in the management field, given that not much research has been undertaken especially in the Ghanaian context. It also provides researchers with an understanding of the concept of leadership ideologies.

\section{References}

Abor, J., \& Bieke, N. (2006). Small business financing initiatives in Ghana. Problems and perspectives in management, 4(3), 69-77.

Abor, J., \& Quartey, P. (2010). Issues in SME development in Ghana and South Africa. International research journal of finance and economics, 39(6), 215-228.

Alexander, J. (2015). The major ideologies of liberalism, socialism and conservatism. Political Studies, 63(5), 980-994. https://doi.org/10.1111/1467-9248.12136

Allen, N. J., \& Meyer, J. P. (1990). The measurement and antecedents of affective, continuance and normative commitment to the organization. Journal of occupational and organizational psychology, 63(1), 1-18. https://doi.org/10.1111/j.2044-8325.1990.tb00506.x

Antoncic, J. A., \& Antoncic, B. (2011). Employee loyalty and its impact on firm growth. International Journal of Management and Information Systems, 15(1), 81. https://doi.org/10.19030/ijmis.v15i1.1598

Anwar, J., \& Hasnu, S. A. F. (2013). Ideology, purpose, core values and leadership: How they influence the vision of an organisation. International Journal of Learning and development, 3(3), 168-184. https://doi.org/10.5296/ijld.v3i3.3642

Bagherian, R., Goodarzi, M., \& Shadfar, S. (2011). Relationship between attitude toward watershed management programs and level of participation. Middle East Journal of Scientific Research, 9(3), 324-329.

Balkin, J. M. (2002). Cultural Software: A theory of ideology. : Yale University Press.

Bass, B. M. (1997). Does the transactional-transformational leadership paradigm transcend organizational and national boundaries? American psychologist, 52(2), 130. https://doi.org/10.1037/0003-066X.52.2.130

Bass, B. M. (1998). The ethics of transformational leadership. Ethics, the heart of leadership, 169-192.

Bono, J. E., \& Judge, T. A. (2004). Personality and transformational and transactional leadership: a meta-analysis. Journal of applied psychology, 89(5), 901. https://doi.org/10.1037/0021-9010.89.5.901

Brace, I. (2008). Questionnaire design: How to plan, structure and write survey material for effective market research: Kogan Page Publishers.

Brockner, J., Tyler, T. R., \& Cooper-Schneider, R. (1992). The influence of prior commitment to an institution on reactions to perceived unfairness: The higher they are, the harder they fall. Administrative Science Quarterly, 241-261. https://doi.org/10.2307/2393223

Bryman, A., \& Bell, E. (2015). Business research methods: Oxford University Press, USA.

Burns, J. M. (1978). Leadership. New York: Harper \& Row.

Campbell, K. (1991). Factoring culture into the women in management equation. Equal Opportunities International, 10(3/4), 53-60. https://doi.org/10.1108/eb010551

Chang, H. F. (2002). The Immigration Paradox: Poverty, Distributive Justice, and Liberal Egalitarianism. DePaul L. Rev., 52, 759 .

Chau, R. (2009). Liberalism: A political philosophy. Mankal Economic Education Foundation,(November: 2009), $1-6$.

Chen, S. (2003). The philosophy of existence and cognition. Journal of Dahan Institute of Technology, 18, 35-52.

Creswell, J. W., \& Clark, V. L. P. (2007). Designing and conducting mixed methods research. Australian and New Zealand Journal of public Health, 31(4), 388. https://doi.org/10.1111/j.1753-6405.2007.00096.x

Daft, R. L. (1998). Organisational theory and decision. Cincinnati, Ohio: South Western College.

De Groot, T., Kiker, D. S., \& Cross, T. c. (2000). A meta analysis to review organisational outcomes related to charismaric leadership. Canadian Journal of Administrative Sciences, 17(4), 356-372. 
https://doi.org/10.1111/j.1936-4490.2000.tb00234.x

De Jong, J. P., \& Den-Hartog, D. N. (2007). How leaders influence employees' innovative behaviour. European Journal of Innovation Management, 10(1), 41-64. https://doi.org/10.1108/14601060710720546

Dessler, G. (1998). Management. Upper Saddle River, NJ: Prentice-Hall International.

Dubinsky, A. J., Yammarino, F. J., Jolson, M. A., \& Spangler, W. D. (1995). Transformational leadership: An initial investigation in sales management. Journal of Personal Selling \& Sales Management, 15(2), 17-31.

Eagly, A. H., \& Chaiken, S. (1998). Attitude structure and function. Boston: McGraw Hill Company.

Elegido, J. M. (2013). Does it make sense to be a loyal employee? Journal of Business Ethics, 116(3), 495-511. https://doi.org/10.1007/s10551-012-1482-4

Gliem, J. A., \& Gliem, R. R. (2003). Calculating, interpreting, and reporting Cronbach's alpha reliability coefficient for Likert-type scales. Paper presented at the Mid West research-to-practice conference in adult, continuing and community education The Ohio State University, Columbus.

Hampden-Turner, C., \& Trompenaars, F. (2000). Building Cross-Cultural Competence. Chichester, UK: J. In: Wiley \& Sons. Google Scholar.

Iqbal, N., Anwar, S., \& Haider, N. (2015). Effect of leadership style on employee performance. Arabian Journal of Business and Management Review, 5(5).

Judge, T. A., \& Bono, J. E. (2000). Five-factor model of personality and transformational leadership. Journal of applied psychology, 85(5), 751. https://doi.org/10.1037/0021-9010.85.5.751

Judge, T. A., \& Piccolo, R. F. (2004). Transformational and transactional leadership: a meta-analytic test of their relative validity. Journal of applied psychology, 89(5), 755. https://doi.org/10.1037/0021-9010.89.5.755

Kieser, A. (2001). Trust as a change agent for capitalism or as ideology? A commentary. Organization Science, 12(2), 241-246. https://doi.org/10.1287/orsc.12.2.241.10109

Koopman, C. (2006). Pragmatism as a philosophy of hope: Emerson, James, Dewey, Rorty. The Journal of Speculative Philosophy, 20(2), 106-116. https://doi.org/10.1353/jsp.2006.0020

Krishnan, V. R. (2005). Transformational leadership and outcomes: Role of relationship duration. Leadership \& Organization Development Journal, 26(6), 442-457. https://doi.org/10.1108/01437730510617654

Kumar, D., \& Shekhar, N. (2012). Perspectives envisaging employee loyalty: A case analysis. Journal of management research, 12(2), 100.

Lipton, M. (1996). Opinion: Demystifying the development of an organizational vision. Sloan management review, 37(4), 83.

Lo, M.-C., Ramayah, T., \& De Run, E. C. (2010). Does transformational leadership style foster commitment to change? The case of higher education in Malaysia. Procedia-Social and Behavioral Sciences, 2(2), 5384-5388. https://doi.org/10.1016/j.sbspro.2010.03.877

Lok, P., \& Crawford, J. (1999). The relationship between commitment and organizational culture, subculture, leadership style and job satisfaction in organizational change and development. Leadership \& Organization Development Journal, 20(7), 365-374. https://doi.org/10.1108/01437739910302524

Lowenstein, K. (1953). 'Political Systems, Ideologies, and Institutions: The Problem of Their Circulation'. The Western Political Quarterly, 6(4), 689-706. https://doi.org/10.2307/443198

Mensah, S. (2004). A review of SME financing schemes in Ghana. Paper presented at the UNIDO regional workshop of financing small and medium scale enterprises, Accra, Ghana.

Meyer, J. P., Becker, T. E., \& Vandenberghe, C. (2004). Employee commitment and motivation: a conceptual analysis and integrative model. Journal of applied psychology, 89(6), 991. https://doi.org/10.1037/0021-9010.89.6.991

Niehoff, B. P., Moorman, R. H., Blakely, G., \& Fuller, J. (2001). The influence of empoerment and job enrichment on employee loyalty in a downsizing environment. Group and Orgnisation Management, 26(1), 93-113. https://doi.org/10.1177/1059601101261006

O'Regan, N., \& Ghobadian, A. (2005). Innovation in SMEs: the impact of strategic orientation and environmental perceptions. International Journal of Productivity and Performance Management, 54(2), 81-97. https://doi.org/10.1108/17410400510576595 
Pesqueux, Y. (2002). Ideology and organization. Paper presented at the Developing philosophy of management-crossing frontiers, Oxford, United Kingdom.

Pfeiffer, R. S. (1992). Owing loyalty to one's employer. Journal of Business Ethics, 11(7), 535-543. https://doi.org/10.1007/BF00881446

Rue, L. W., \& Byars, L. L. (2003). Management: skills and application. Boston: McGraw-Hill Irwin.

Saunders, M. N., \& Lewis, P. (2012). Doing research in business \& management: An essential guide to planning your project: Pearson.

Scruton, R. (1984). Public space and the classical vernacular. The Public Interest, (74), 5.

Simmon, H. A. (1979). Relational decison making in business organisations. The American Economic Review, 69(4), 493-513.

Stove, D. (2003). Why You Should Be Conservative. D. Stove, On Enlightenment. London: Transaction, 171-178.

Teal, F. (2002). Background Information On Use Of Dataset: Regional Project On Enterprise Development (RPED) Ghana Manufacturing Sector Survey Waves IV (1992-98). Centre for the Study of African Economies, Institute of Economics and Statistics, University of Oxford, St. Cross Building, Manor Road, Oxford, OX1 3UL.

Tims, M., Bakker, A. B., \& Xanthopoulou, D. (2011). Do transformational leaders enhance their followers' daily work engagement? The Leadership Quarterly, 22(1), 121-131. https://doi.org/10.1016/j.leaqua.2010.12.011

Van Dijk, T. A. (2004). Discourse, knowledge and ideology. Communicating Ideologies. Frankfurt/M.: Peter Lang, 5-38.

Visagie, C. M. (2010). The relationship between employee attitudes towards planned organisational change and organisational commitment: an investigation of a selected case within the South African telecommunications industry. (Master of Technology), Cape Perninsula University of Technology,

Walsh, A., \& Ellis, L. (2004). Ideology: Criminology's Achilles' heel? Quarterly Journal of Ideology, 27(112), $1-5$.

Wang, P., \& Zhu, W. (2011). Mediating role of creative identity in the influence of transformational leadership on creativity: Is there a multilevel effect? Journal of Leadership \& Organizational Studies, 18(1), 25-39. https://doi.org/10.1177/1548051810368549

Weiss, R. M., \& Miller, L. E. (1987). The concept of ideology in organizational analysis: The sociology of knowledge or the social psychology of beliefs? Academy of Management Review, 12(1), 104-116. https://doi.org/10.5465/amr.1987.4306492

Wellington, D. C. (2002). Inventions, capitalist wealth and liberal think. International Journal of Social Economics, 29(10), 806-812. https://doi.org/10.1108/03068290210444430

\section{Copyrights}

Copyright for this article is retained by the author(s), with first publication rights granted to the journal.

This is an open-access article distributed under the terms and conditions of the Creative Commons Attribution license (http://creativecommons.org/licenses/by/4.0/). 